\title{
RECYCLEMAX: UM APLICATIVO MOBILE PARA AUXILIAR NO PROCESSO EDUCATIVO DE COLETA SELETIVA
}

\section{RECYCLEMAX: A MOBILE APPLICATION TO HELP IN THE EDUCATIONAL PROCESS OF SELECTIVE COLLECTION}

\author{
Alexsander Matheus Amorim de Oliveira ${ }^{1}$, Gylnara Kylma Feitosa Carvalhêdo Almeida ${ }^{2}$, \\ Yonara Costa Magalhães ${ }^{3}$, Will Ribamar Mendes Almeida ${ }^{4}$.
}

\begin{abstract}
RESUMO. Grande parte dos alunos que estudam educação ambiental não conseguem aplicar de forma prática a coleta seletiva. Esta dificuldade ocorre, muitas vezes, em função da forma pela qual esse ensino é realizado. O objetivo desse estudo o é desenvolvimento de um jogo educativo Mobile, RecycleMax, para o ensino da coleta seletiva de forma lúdica, estimulando e facilitando a aprendizagem do aluno. Para o desenvolvimento do RecycleMax, foi utilizada a ferramenta Construct2, tendo sido seus estudos fundamentados em teorias da computação e de outros trabalhos correlatos na área. Além disso, ocorreu a modelagem do aplicativo por meio do levantamento dos requisitos e a elaboração da estrutura de projetos de software por meio da Linguagem de Modelagem Unificada (UML).
\end{abstract}

PALAVRAS-CHAVE: Aplicação Móvel. Coleta Seletiva. Ambiente Educacional.

\begin{abstract}
Most of the students who study environmental education don't apply in a practical way the selective collection. This difficulty occurs', many times, as to function of the form in which this teaching is performed. The goal of this study is the development of a mobile educative game, called RecycleMax, for the teaching of selective collection of playful way so stimulating and making easy the student's learning. In order to develop the RecycleMax, it was used a Construct 2 tool, and its studies were based in computing theories and form other correlated works in the area. In addition, modeling of the application occurred by means of the survey of the requirements and the elaboration of the structure of software projects through the Unified Modeling Language (UML).
\end{abstract}

KEYWORDS: Mobile Application. Selective Collection. Environment Educational.

\footnotetext{
${ }^{1}$ Bacharel em Sistema de Informação. Egresso da Universidade Ceuma. E-mail: alexsander8400matheus@gmail.com

${ }^{2}$ Mestranda em Meio Ambiente pela Universidade Ceuma. Professora da Universidade Ceuma. E-mail: gylnara@gmail.com

${ }^{3}$ Mestre em Engenharia de Eletricidade pela UFMA. Professora da Universidade Ceuma. E-mail: yonara.magalhaes@ ceuma.br

${ }^{4}$ Doutor em Engenharia de Eletricidade pela Universidade Federal de Campina Grande. Professor da Universidade Ceuma. E-mail: will75@gmail.com
} 


\section{INTRODUÇÃO}

A sociedade está cada vez mais marcada pelas consequências da ação antrópica na natureza. Desastres ambientais, alterações no clima, escassez dos recursos naturais e diversos outros problemas, oriundos da intensa intervenção do homem na natureza, há muito tempo fazem parte do nosso cotidiano.

A falta de informação é o principal agente do agravamento dos impactos ambientais, visto que a maior parte da população não tem consciência de que também é parte integrante do meio ambiente e que, assim como a diversidade biológica, a sua qualidade de vida também é afetada pelos problemas ambientais. Logo, a educação ambiental assume cada vez mais uma função transformadora, na qual a responsabilização dos indivíduos torna-se um objetivo essencial para promover um novo tipo de desenvolvimento - o desenvolvimento sustentável (JACOBI 2003).

É nesse contexto que a utilização de jogos eletrônicos se torna importante no que se refere às novas metodologias de ensino, por proporcionar ao aluno uma aprendizagem mais divertida e interativa, apresentando possibilidades criativas e de significativa densidade, pois permite que o estudante/jogador se sinta como parte integrante do contexto do jogo, aprendendo enquanto se diverte.

Este trabalho se propõe a construção de um jogo educativo, cujo objetivo é desenvolver a consciência ambiental no jogador através do ensino da coleta seletiva, despertando-lhe o senso de preservação ambiental do local onde vive. Para construção do trabalho proposto será feita uma série de estudos para fundamentação teórica, levantamento de requisitos e construção do protótipo através da plataforma Construct 2, que é um software livre para construção de jogos em duas dimensões. Este aplicativo será chamado de RecycleMax.

Pesquisas relacionadas ao tema apontam para outros projetos, que têm o mesmo objetivo de despertar a consciência ecológica, dentre os quais pode-se exemplificar o "Coleta Seletiva: Educação ambiental com webcam game" de Souza, Jr E. (2009). Este trabalho propõe a interação com webcam game, que é uma modalidade cuja jogabilidade inclui um computador, uma câmeram, webcam e um projetor, sendo voltado ao ensino da coleta seletiva para crianças que utilizaram uma espécie de controle que indica a direção do lixo reciclável. O outro trabalho que possui destaque é o "UruBurbanos: um Jogo para Apoiar o Ensino-Aprendizagem de Educação Ambiental” (Souza. et al. 2011), projeto este que utiliza um jogo em 3D para ensinar aos moradores locais a importância da educação ambiental e o jogo A Fazenda (Silva \& Passerino, 2007) apresenta a modelagem de uma aplicação educacional, voltada à Educação Ambiental. 
A partir destes trabalhos conclui-se que a educação ambiental, utilizando-se da tecnologia é meio muito propício para ser explorada e expandida. A proposta em questão também tem o objetivo de contribuir para ensino de forma lúdica e educativa da educação ambiental e torna mais acessível a prática de coleta seletiva. Mas o que torna este trabalho diferente é a utilização de dispositivos móveis para tal tarefa, esta modalidade é pouco explorado ou explorado como um objetivo secundário em aplicativos móveis.

\section{FUNDAMENTAÇÃO TEÓRICA}

A educação ambiental apareceu pela primeira vez na Grã-Bretanha em 1965, durante a Conferência em Educação na Universidade de Keele onde se definiu que a educação ambiental deveria estar presente na educação de todos os cidadãos (Dias, 2003).

No Brasil, o Ministério da Educação (MEC) em 1998, elaborou um documento que servia de modelo referencial, um guia não obrigatório de ser seguido, denominado Referencial Curricular Nacional para a Educação Infantil (RCNEI) e que, em seu terceiro volume, trazia um capítulo sobre "Natureza e Sociedade", com orientações sobre como os professores devem ministrar as relações existentes entre ambos. Segundo o RCNEI, o "trabalho com os conhecimentos derivados das Ciências Humanas e Naturais deve ser voltado para a ampliação das experiências das crianças e para a construção de conhecimentos diversificados sobre o meio social e natural” (BRASIL, 1998, p. 166) e " [...] exemplo de atividade permanente são os cuidados com o meio ambiente, relacionados à organização e conservação dos materiais e espaços coletivos, à coleta seletiva de lixo, à economia de energia e água etc.” (BRASIL, 1998, p. 200).

A proposta a ser desenvolvida é associar a utilização de jogos eletrônicos educativos ao ensino, que possui grande importância, com a educação ambiental, especificamente a coleta seletiva, através de um jogo elaborado para dispositivos móveis para o sistema operacional Android, objetivando incentivar e ensinar a importância da coleta seletiva e a reciclagem do lixo.

O conceito educacional dos jogos é observado com muitas controvérsias, as quais estão relacionadas basicamente por duas funções: uma é a função lúdica, pois o jogo propicia a diversão, o prazer; e a outra é a função educativa, onde o jogo tenta trazer uma aprendizagem que complete o indivíduo em seu saber, seus conhecimentos e suas relações com o meio que habita. É nesse meio termo que se encontram os jogos educativos, os quais além de ter o objetivo de propiciar a diversão, tentam trazer uma mensagem educativa para ser desenvolvida.

Existem diversos estudos e experiências pedagógicas que tiveram como objetivo o estudo da utilização dos aparelhos celulares nos ensinos de diversas áreas do conhecimento e nos diferentes 
níveis de ensino. Segundo Junior (2012, p. 136), “[..] com um dispositivo móvel, o professor poderá criar estratégias didáticas para envolver seus alunos em diversas situações de aprendizagem, bem como criar possibilidades e estratégias para favorecer suas práticas".

Oportunizar esse acesso à tecnologia com o propósito de ensinar a importância da coleta seletiva pode promover um interesse por parte das crianças e muitas vantagens podem ser observadas como aponta os estudos de Junior, J. B. B. (2012) para utilização dos dispositivos, das quais citam-se:

- São leves e relativamente menores que dispositivos "fixos";

- A possibilidade de adquirirem diversas aplicações que fazem com que o dispositivo se torne mais completo e funcional, a ponto dos professores poderem trabalhar de forma exploratória os aplicativos de forma pedagógica;

- Oferece ao usuário conectividade, portabilidade de conteúdo;

- Facilita a comunicação entre as pessoas;

- Favorece aos alunos experiências ativas de aprendizagem com equipamentos modernos e do interesse geral;

- Em certos casos, se cada aluno possuir seus próprios dispositivos, a instituição de ensino pode até descartar a necessidade de laboratórios de informática e poderia investir em uma melhor conexão com a internet para promover aulas mais interativas e dinâmicas.

Porém, observa-se que, como todas tecnologias, os dispositivos móveis possuem desvantagens que devem ser observadas e estudadas antes da sua implantação. Dentre elas:

- O contato entre as pessoas diminui, uma vez que permanecem conectados durante horas;

- A facilidade do atendimento a multitarefa que os dispositivos proporcionam, o que pode provocar a distração dos alunos e, consequentemente, um menor aproveitamento da aula.

A utilização dos dispositivos móveis é o instrumento necessário, pois o jogo é desenvolvido para esta plataforma devido as vantagens da portabilidade e voltado para o sistema operacional Android, devido a sua popularidade, e utilizando o software construtor de aplicações Android, o Construct2. O Construct2 é uma ferramenta para desenvolvimento de jogos, desenvolvida pelo grupo Scirra e que possui uma licença livre que pode ser utilizada para desenvolvimento. Sua principal vantagem é a utilização baseada apenas na lógica de programação, sem que haja qualquer linguagem de programação associada. Sua manipulação é intuitiva e simples e ocorre por meio de trocas de layout do menu, que determinam o comportamento, dimensões e todo aspecto físico do sprite que é adicionado (seção 1 da Figura 1); o layout de ação, que coordena 
todos os possíveis eventos que são descritos pelo desenvolvedor (seção 2 da Figura 1): e por uma área central da qual se observam todos os aspectos visuais do jogo (seção 3 da Figura 2).

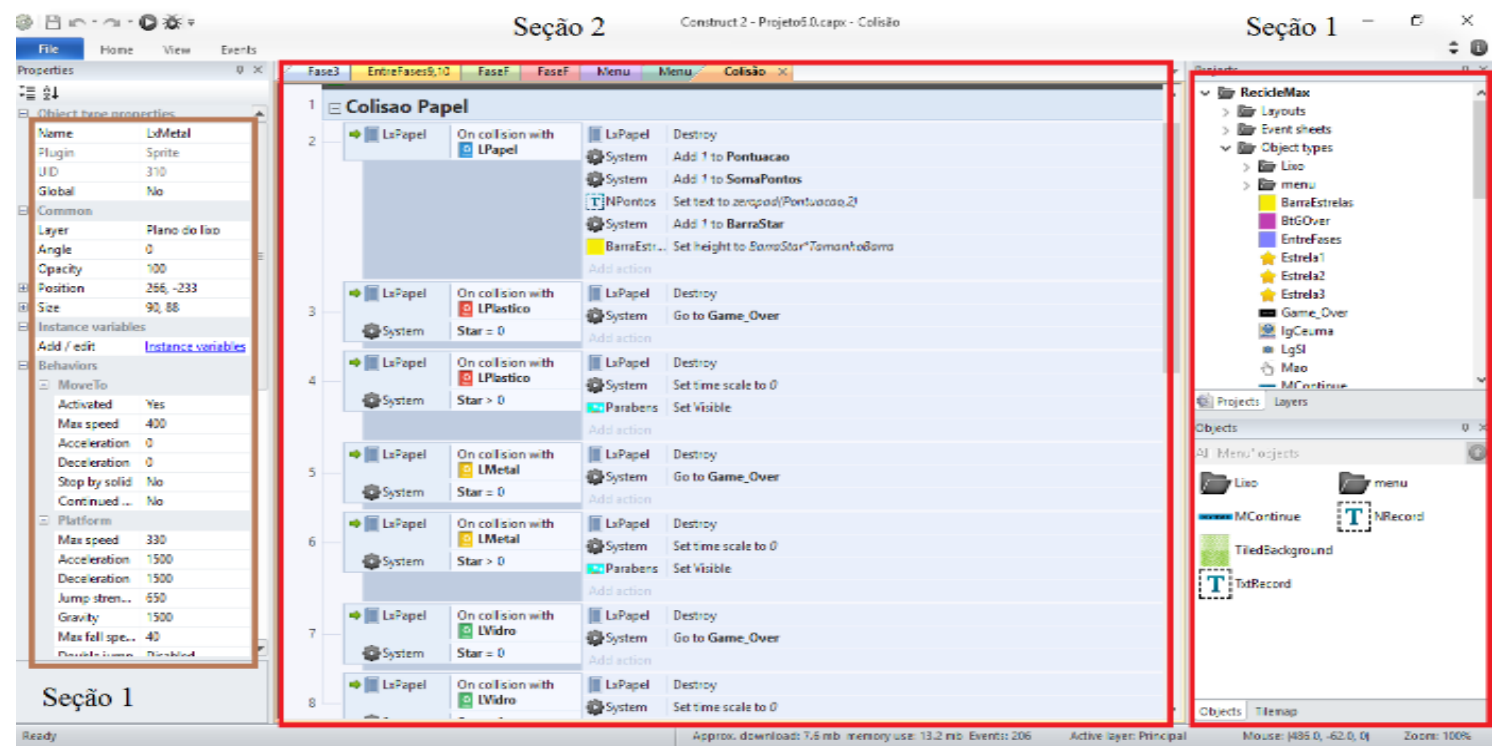

Figura 1: Seção de layout de menu e de ação do Construct2

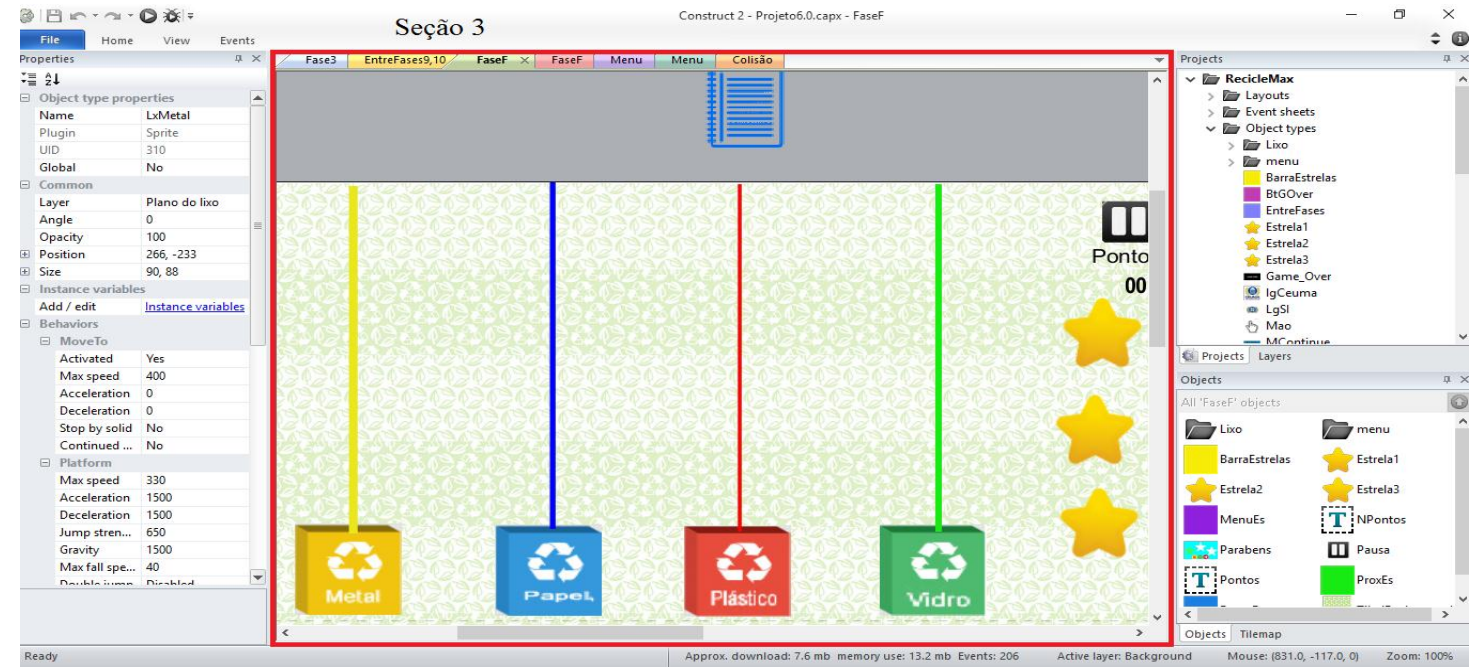

Figura 2: Seção de layout da área central do Construct2

\section{METODOLOGIA}

Para efetivação deste trabalho, foi realizada uma pesquisa qualitativa de cunho documental a partir de livros, sites e artigos especializados no assunto, além de outros projetos já desenvolvidos com esse objetivo sobre o processo da reciclagem e as medidas que vêm contribuindo para a preservação do meio ambiente, bem como vídeos de aulas, disponibilizadas na plataforma do Youtube, para auxiliar o entendimento do Construct2. O desenvolvimento do jogo seguiu as etapas 
de: Análise de Requisitos, Projeto e Construção do protótipo. Utilizou-se o programa Cronstruc2 para desenvolvimento do jogo, pois sua linguagem se baseia no teste de condições predefinidas, chamados de "evento", sendo que cada evento resulta em uma ação que também é predefinida. A exemplo, Evento: caso o jogador direcione o lixo para a lixeira correta, resulta no aumento de pontos. Desta forma, todos eventos resultam em uma ação/reação do jogo.

\section{ANÁLISE DOS RESULTADOS E DISCUSSÕES}

Após as pesquisas por documentos que pudessem embasar este trabalho e a partir de reflexões, foi possível reconhecer que os jogos que promoviam o foco na educação ambiental têm como resultado uma eficiência para o processo de ensino/aprendizagem e assimilação significativa dos conceitos que foram apresentados. Como exemplo, tem-se "UruBurbanos: um Jogo para Apoiar o Ensino-Aprendizagem de Educação Ambiental" (SOUZA 2011), que obteve êxito nos itens avaliados e considerou que UruBurbanos uma ferramenta computacional educativa para aprendizagem da educação ambiental.

Neste trabalho, assumiu-se uma única modalidade de jogo, que é a escolha do percurso correto do objeto reciclável até sua lixeira correspondente. Estão disponíveis no jogo materiais reciclados como: caixas de papel, garrafas de vidro, copos plástico e latas de alumínio. Os materiais recicláveis são objetos deste ambiente e são dispostos de forma aleatórias.

Para construção desse protótipo na plataforma do Construct2, foram necessárias a procura de sprites (ícones com os quais o jogador pode interagir durante sua jogada). Para tornar a aprendizagem mais simples foram escolhidos sprites como: folha de papel, lata metálica, garrafa de vidro e copo com canudo plástico, que serviram como os primeiros objetos a serem jogados. Vale ressaltar que as cores utilizadas estão de acordo com o padrão de cores utilizado nas lixeiras da coleta seletiva adotadas no Brasil, sendo: Papel - Azul, Plástico - Vermelho, Vidro - Verde, Metal - Amarelo. E, à medida que o jogador avança nas fases, há a introdução de novos objetos com tonalidades diferentes.

\section{Tela inicial do jogo RecycleMax}

A tela inicial do jogo apresenta um menu composto por 4 opções "Novo Jogo", “Continue", "Opções” e "Créditos” (Figura 3). 


\section{Recyclemax}

NOVIO JO(O)

\section{CON'IINUIE}

DPCִÕIS

\section{CIRÉDITOS}

Figura 3 - Tela de Menu.

\section{$\underline{\text { Novo Jogo }}$}

A partir da escolha de "Novo Jogo", o jogador é direcionado à primeira fase, que possui um pequeno esquema de utilização do jogo, com o objetivo de ensinar como jogar. Esta fase é composta por três lixeiras (da esquerda para direita): metal (lixeira amarela), papel (lixeira azul) e plástico (lixeira vermelha) (Figura 4).

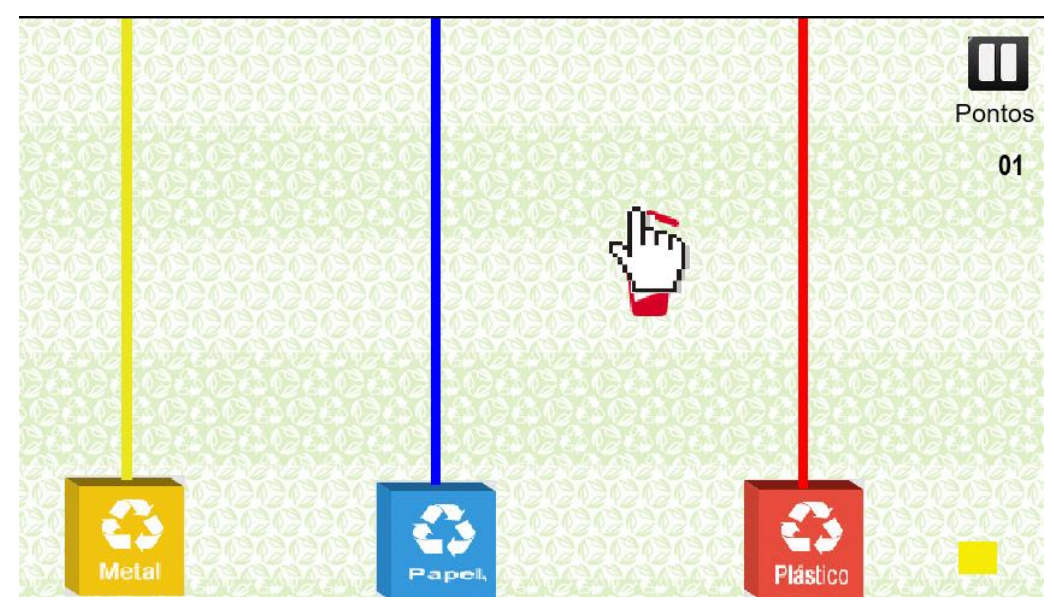

Figura 4 - Tela da fase 1 do jogo.

\section{$\underline{\text { Iniciar Jogo }}$}

Cada objeto é apresentado ao jogador no sistema up-down (de cima para baixo). E à medida que os objetos vão sendo visualizados devem ser direcionados para a lixeira correta. Ao clicar sobre o objeto, este é selecionado (Figura 5) e estará em deslocamento vertical, sendo necessário redirecioná-lo para a lixeira correspondente. Ao acertar a lixeira, pontos serão acumulados (Figura 6). 


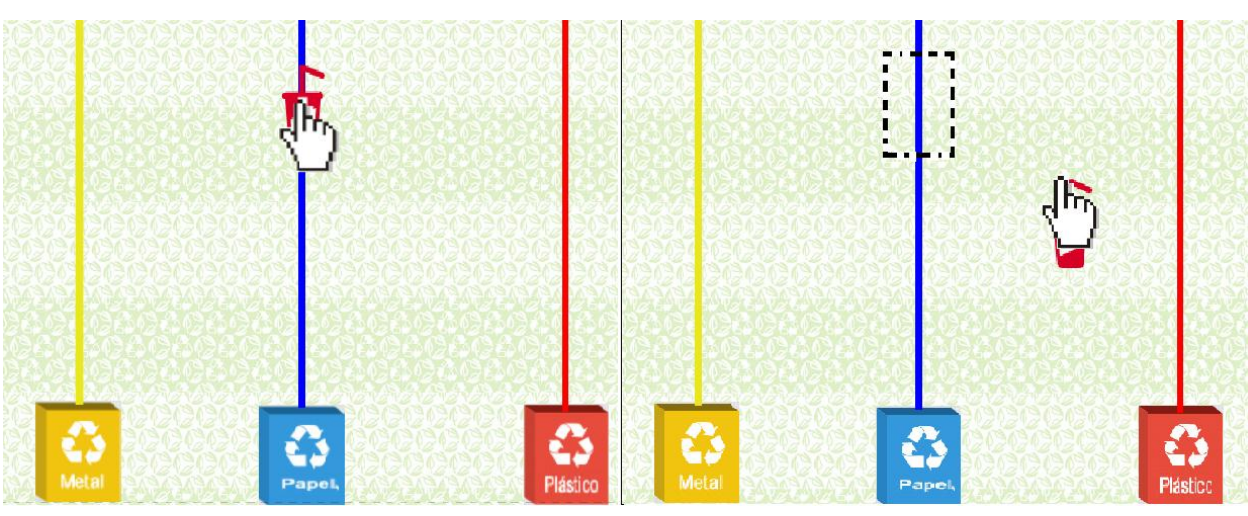

Figura 5: Reposicionamento do objeto lixo para a respectiva lixeira

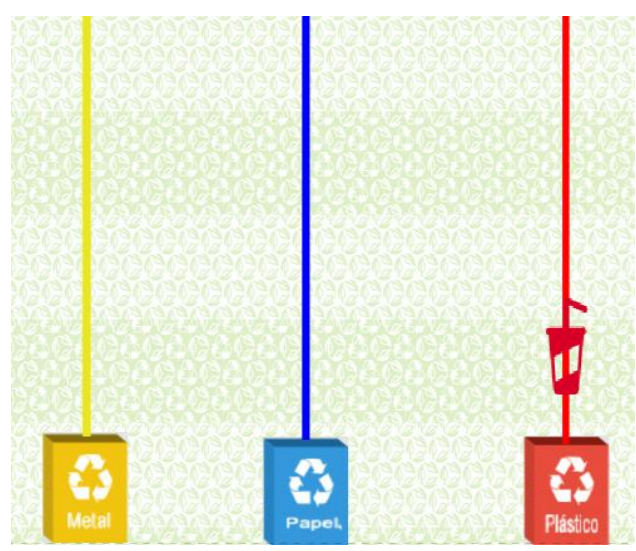

Figura 6: Reposicionamento do objeto

À medida que o jogador progride nas fases do jogo é adicionada uma quarta lixeira (Vidro) e seus respectivos objetos representantes também são introduzidos. As fases são compostas por uma quantidade definida de objetos e por um tempo definido entre o surgimento dos objetos ao jogador. À medida que o jogador avança de fase, a quantidade de objetos aumenta e o intervalo entre as aparições diminui, permitindo que o jogador se sinta cada vez mais desafiado. Outra ação importante que ocorre no jogo e que contribui para aprendizagem das questões ambientais é que no momento da troca de fases, são apresentadas diversas mensagens com o objetivo de incentivar e ensinar a importância da reciclagem (Figura 7).

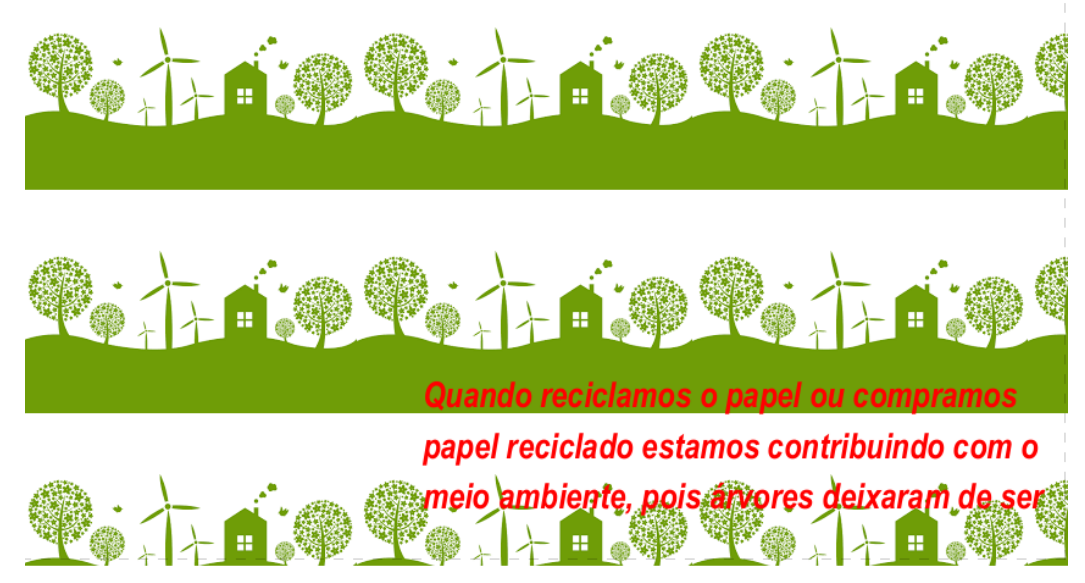

Figura 7: Mensagens 


\section{Visualizar informações de créditos do jogo}

A opção "Crédito" apresenta ao jogador uma tela com as informações sobre a plataforma do jogo, sobre o desenvolvedor e sobre o record do jogo (score de pontos máximos já obtidos) (Figura 8).

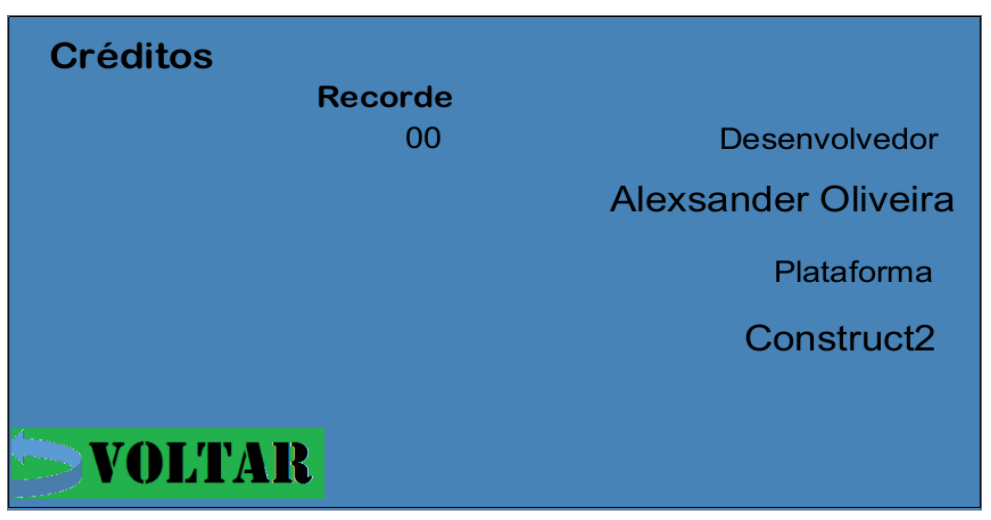

Figura 8: Tela de crédito do RecycleMax

$\underline{\text { Opções do jogo }}$

Na tela de opções, é apresentado o menu de acesso ao volume de música e também sobre o efeito utilizado no jogo (Figura 9).

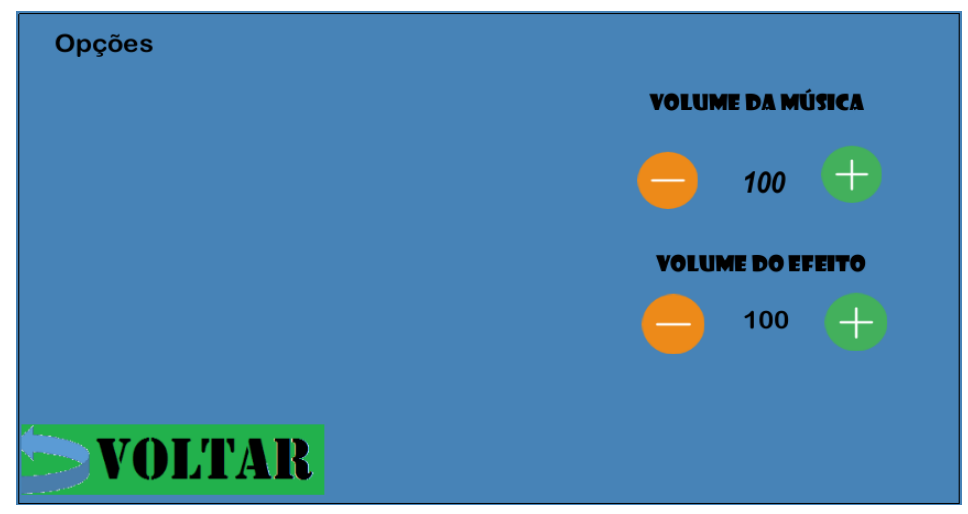

Figura 9: Tela de opções

\section{CONCLUSÃO}

A construção do RecycleMax, como proposta de um jogo educativo para dispositivos móveis, disponibilizará mais uma aplicação para contribuir com a educação ambiental, especificamente quanto a importância da coleta seletiva de lixo. Esta ferramenta poderá ser útil para ensino nas escolas, e fora dela, ao introduzir esta aprendizagem por meio da utilização dos dispositivos móveis, o que torna esta solução um diferencial quanto às metodologias de estudos anteriores, em que são utilizados computadores de mesa ou desktops.

A construção deste jogo educativo pode servir de ferramenta pedagógica para ensino de educação infantil com relação ao tema da coleta seletiva, além de promover a conscientização da 
importância da preservação ambiental para que as gerações posteriores possam desenvolver hábitos de conservação do ambiente. A sociedade precisa de cidades sustentáveis. Para tanto, a educação é um passo fundamental. Este trabalho também pode servir de complemento a estudos de outros trabalhos relacionados a área do conhecimento. Em resumo, este trabalho pode oferecer uma jogabilidade simples, ensino da coleta seletiva, e na palma da mão, para qualquer momento e qualquer lugar.

\section{REFERÊNCIAS}

BRASIL. (1998) "Referencial curricular nacional para a educação infantil”". Ministério da Educação e do Desporto, Secretaria de Educação Fundamental. Brasília: MEC/SEF. 3 v. Disponível em < http://portal.mec.gov.br/seb/arquivos/pdf/volume3.pdf> acessado em 01 Nov 2016

BRASIL. (2001) “Parâmetros Curriculares Nacionais”. Ministério da Educação. Brasília: MEC. Volume 9.1. Disponível em < http://portal.mec.gov.br/seb/arquivos/pdf/livro091.pdf > acessado em 12 Out 2016.

DIAS, G. F. (2003) “Educação Ambiental: princípios e práticas”. 8. ed. São Paulo: Gaia.

JACOBI, P. (2003) Educação Ambiental, Cidadania e Sustentabilidade. São Paulo: Campinas. Disponível em <http://www.scielo.br/pdf/cp/n118/16834.pdf>.

JUNIOR, J. B. B. (2012) "Do Computador ao Tablet: Vantagens Pedagógicas na Utilização de Dispositivos Móveis na Educação”. Revista EducaOnline Volume 6 - No 1.

PEREIRA, W. R. F. (2013). "Reflexão sobre o uso de tecnologias da educação no ensino superior". Revista Intersaberes Volume 8 - No 16.

SCARDUA, V. M. (2015) "Crianças e Meio Ambiente: A Importância da Educação Ambiental na Educação Infantil. Disponível em $<$ http://facevv.cnec.br/wpcontent/uploads/sites/52/2015/10/CRIAN\%C3\%87AS-E-MEIO-AMBIENTE-AIMPORT\%C3\%82NCIA-DA-EDUCA\%C3\%87\%C3\%83O-AMBIENTAL-NAEDUCA\%C3\%87\%C3\%83O.pdf > acessado em 01 Nov 2016.

SCIRRA. FEATURES CONTRUCT 2. SCIRRA, (2015). Disponível em:< https://www.scirra.com/construct2>. Acesso em:14 jun. 2016.

SILVA, A. A., Passerino, L. M. A Fazenda: Software Educativo para a Educação Ambiental. CINTED-UFRGS, Novas Tecnologias na Educação. v. 5 nº 2. 2007.

SOUZA JR., E. et al. (2009). Coleta Seletiva: Educação ambiental com webcam game. In: VIII Brazilian Symposium on Games and Digital Entertainment. Rio de Janeiro-RJ, Brasil. 
SOUZA et al. (2011). UruBurbanos: um Jogo para Apoiar o Ensino-Aprendizagem de

Educação Ambiental. In: VIII Brazilian Symposium on Games and Digital Entertainment. Salvador-BA, Brasil. 